\title{
The rate of polymyalgia rheumatica (PMR) and remitting seronegative symmetrical synovitis with pitting edema (RS3PE) syndrome in a clinic where primary care physicians are working in Japan
}

\author{
Toshikatsu Okumura $\cdot$ Satoshi Tanno $\cdot$ \\ Masumi Ohhira $\cdot$ Tsukasa Nozu
}

Received: 26 October 2010 / Accepted: 18 February 2011 / Published online: 24 March 2011

(C) The Author(s) 2011. This article is published with open access at Springerlink.com

\begin{abstract}
We analyzed the rate of polymyalgia rheumatica (PMR) and remitting seronegative symmetrical synovitis with pitting edema (RS3PE) syndrome, both characterized as seronegative inflammatory arthritis in elderly, in an outpatient unit where primary care physicians are working in Japan to better understand the epidemiological characteristics of the diseases in Japan. Consecutive outpatients who newly visited at Department of General Medicine, Asahikawa Medical University Hospital, Japan, between April 2004 and March 2010 were analyzed. Each parameter such as age, sex, diagnosis, and biochemical examination was investigated. During the 6 years, 10 or 3 patients were diagnosed as PMR or RS3PE syndrome, respectively. The patients with PMR were 7 women and 3 men, and the average age at diagnosis was 69 . Out of all patients aged over $50(n=3,347)$, the rate of PMR was $0.22 \%$ in men or $0.36 \%$ in women, respectively. On the other hand, RS3PE syndrome was diagnosed in 3 men $(76,76$, and 81 years old). The rate of patients with RS3PE syndrome was $0.09 \%$ among outpatients aged over 50 indicating that the rate of PMR in an outpatient clinic in Japan is not far from previous findings reported from western countries. When compared with PMR, the rate of RS3PE syndrome was approximately one-third, providing for the first time the rate of RS3PE syndrome when compared with PMR. These epidemilogical data might help us pick up the diseases in primary care setting in Japan.
\end{abstract}

T. Okumura $(\bowtie) \cdot S$. Tanno $\cdot$ M. Ohhira $\cdot$ T. Nozu

Department of General Medicine, Asahikawa Medical University, 2-1-1 Midorigaoka-Higashi, Asahikawa 078-8510, Japan

e-mail: okumurat@asahikawa-med.ac.jp
Keywords Polymyalgia rheumatica (PMR) $\cdot$ Remitting seronegative symmetrical synovitis with pitting edema (RS3PE) syndrome · Primary care · Japan · Epidemiology

\section{Introduction}

Polymyalgia rheumatica (PMR) is one of the most widespread inflammatory rheumatic disease affecting people aged over 50 and characterized by pain and morning stiffness in the neck, shoulder, and pelvic girdle [1]. PMR is generally regarded as a benign disease with no adverse impact on long-term survival [2,3] and represents one of the most common indicators for long-term steroid therapy in the community [4, 5]. Patients with PMR are subjected to wide variations in clinical practice and may be managed in primary or secondary care by general practitioners $[6,7]$. A couple of studies demonstrated the prevalence of PMR in USA and Canada [8-10]. With regard to the reports on PMR in Japan, there are some clinical studies on patients with PMR. For example, five independent research groups demonstrated clinical features in $29,13,7,44$, or 32 patients with PMR in Japan, respectively [11-15]. Thus, PMR is observed commonly in Japan. However, the prevalence of the disease is not so far known.

Increasing evidence has suggested that remitting seronegative symmetrical synovitis with pitting edema (RS3PE) syndrome is also one of the inflammatory rheumatic disease of the elderly [16]. RS3PE was described in 1985 by McCarty et al. as an original subgroup of seronegative rheumatoid arthritis [17]. It occurred especially in men older than 60 . The onset of the disease was sudden and characterized by a symmetrical polyarthritis associated with pitting edema of the extremities of the upper and lower limbs. According to the report by Olivieri et al. [16], the 
following diagnostic criteria for this syndrome had been proposed. These include the following: (1) bilateral pitting edema of both hands, (2) sudden onset of polyarthritis, (3) age more than 50, and (4) seronegative rheumatoid factor. So far, there are some papers that show patients with RS3PE syndrome in Japan. A couple of independent research groups have demonstrated 7, 13, 11, or 3 Japanese patients with RS3PE syndrome [18-21]. Thus, RS3PE syndrome is not very rare in Japan. However, the prevalence of the disease in Japan is not known. Thus, little is known about the epidemiologic feature in patients with PMR and RS3PE syndrome, both characterized as seronegative inflammatory arthritis in elderly $[1,17]$. According to the study by Kremers [7], generalists provide the majority of care for patients with PMR. Rheumatologist involvement is generally limited to diagnostic confirmation and management of complications. Thus, primary care physicians have to pay attention to accurately diagnose PMR in the daily practice. A retrospective chart review of 123 PMR patients referred to a tertiary care rheumatology clinic in Canada demonstrated that the accuracy of PMR diagnosis by non-rheumatologists was very low (24\%), and that a large number of inappropriate tests were performed by nonrheumatologists in an effort to reach diagnosis [22]. It is therefore important for general practitioners to understand epidemiological characteristics of PMR in addition to diagnose the disease accurately. Based on this evidence, the present study was performed to clarify the rate of Japanese patients with PMR or RS3PE syndrome in a clinic where primary care physicians are working in Japan.

\section{Patients and Methods}

We analyzed consecutive outpatients who newly visited at Department of General Medicine, Asahikawa Medical University Hospital between April 2004 and March 2010. As we have recently demonstrated [23, 24], the hospital consists of 602 beds in which approximately 250 doctors are working to cover almost all of the medical problems. Among them, 5 or 6 primary care physicians are working at the Department of General Medicine. All data were drawn from medical records and computerized physician order entry system in the hospital. Each parameter such as age, sex, and diagnosis was investigated from the source.

PMR was diagnosed according to the previous reports $[14,25,26]$. They fulfilled the following clinical and laboratory conditions; age older than 50; suffering from severe myalgia and/or stiffness of bilateral neck, shoulders and pelvic girdle for at least 2 weeks; bilateral upper arm tenderness; a marked increased erythrocyte sedimentation rate $(\mathrm{ESR}>50 \mathrm{~mm} / \mathrm{h})$. Normal serum creatinine kinase $(\mathrm{CK})$ concentration, and negative for rheumatoid factor (RF) and antinuclear factor (ANA), and a dramatic response to low doses of corticosteroid are observed. According to a previous report [27], patients were included as RS3PE syndrome if they were older than 50 and satisfied the following diagnostic criteria: symmetrical polyarthritis, pitting edema of the bilateral hands and foots, serological absence of RF, and a fast response to steroid therapy.

\section{Results}

Out of 6,868 patients, PMR or RS3PE syndrome was diagnosed in $10(0.15 \%)$ or $3(0.04 \%)$ patients, respectively. Table 1 shows the clinical characteristics of 10 patients with PMR in this study. The patients with PMR ranged from 58 to 82 years old, and were 7 women and 3 men. The average age at diagnosis was 69 years old. All patients had suffered from severe myalgia in at least two parts of the body including the neck, shoulders, and pelvic girdle. The myalgia had persisted for 1-4 months. ESR at initial phase was over $50 \mathrm{~mm} / \mathrm{h}$ in all patients. RF was negative in all 10 cases. They responded well to PSL at doses of 5-15 mg/day.

On the other hand, RS3PE syndrome was diagnosed in 3 men (76, 76, and 81 years old) in this study. Female patients with RS3PE syndrome have never observed in this analysis. Onset of appearance of edema in extremities with myalgia was sudden in all patients. Clinical characteristics of 3 patients with RS3PE syndrome are showed in Table 2. CRP level was elevated in all cases. However, ESR was high in two cases (No1 and No.2) but normal in one case (No.3). Two patients (No. 1 and No. 3 in Table 2) were initially treated with 20 or $15 \mathrm{mg} /$ day of PSL. The response to the dose of PSL was excellent in the two cases within first week. On the other hand, PSL at the dose of $30 \mathrm{mg}$ was not effective in a patient (No. 2). The patient (No. 2) had been

Table 1 Clinical characteristics of 10 patients with polymyalgia rheumatica (PMR)

\begin{tabular}{lllrcll}
\hline Age & Gender & $\begin{array}{l}\text { Symptom } \\
\text { duration } \\
\text { (months) }\end{array}$ & $\begin{array}{l}\text { WBC } \\
\left(/ \mathrm{mm}^{3}\right)\end{array}$ & $\begin{array}{l}\text { CRP } \\
(\mathrm{mg} / \mathrm{dl})\end{array}$ & $\begin{array}{l}\text { ESR } \\
(\mathrm{mm} / \mathrm{h})\end{array}$ & $\begin{array}{l}\text { PSL } \\
\text { dose }(\mathrm{mg})\end{array}$ \\
\hline 69 & $\mathrm{~F}$ & 1 & 7,690 & 1.18 & 85 & 5 \\
82 & $\mathrm{~F}$ & 2 & 9,520 & 15.35 & 87 & 5 \\
76 & $\mathrm{M}$ & 3 & 5,030 & 5.1 & 85 & 10 \\
58 & $\mathrm{~F}$ & 4 & 6,100 & 10.3 & 98 & 15 \\
68 & $\mathrm{M}$ & 1 & 5,550 & 3.53 & 84 & 15 \\
70 & $\mathrm{~F}$ & 5 & 8,210 & 4.89 & 79 & 5 \\
58 & $\mathrm{~F}$ & 1 & 10,870 & 5.95 & 94 & 10 \\
73 & $\mathrm{~F}$ & 2 & 6,180 & 8.66 & 94 & 10 \\
75 & $\mathrm{~F}$ & 1 & 6,010 & 4.15 & 91 & 15 \\
67 & $\mathrm{M}$ & 2 & 6,840 & 0.67 & 56 & 15 \\
\hline
\end{tabular}

PSL predonisolone 
Table 2 Clinical characteristics of 3 patients with remitting seronegative symmetrical synovitis with pitting edema (RS3PE)

\begin{tabular}{llllllll}
\hline No. Age Gender & $\begin{array}{l}\text { Symptom } \\
\text { duration } \\
\text { (months) }\end{array}$ & $\begin{array}{l}\text { WBC } \\
(/ \mathrm{mm})\end{array}$ & $\begin{array}{l}\text { CRP } \\
(\mathrm{mg} / \mathrm{dl})\end{array}$ & $\begin{array}{l}\text { ESR } \\
(\mathrm{mm} / \mathrm{h})\end{array}$ & $\begin{array}{l}\text { PSL } \\
\text { dose }(\mathrm{mg})\end{array}$ \\
\hline 1. & 76 & $\mathrm{M}$ & 2 & 6,580 & 5.1 & 61 & 20 \\
2. & 82 & $\mathrm{M}$ & 1 & 8,750 & 9.82 & 88 & $30^{*}$ \\
3. & 76 & $\mathrm{M}$ & 2 & 6,690 & 0.47 & 4 & 15 \\
\hline
\end{tabular}

* This patient did not respond to PSL probably because of paraneoplastic (prostate cancer) factor-induced disease

$P S L$ predonisolone

diagnosed as prostate cancer approximately 10 years ago by a doctor in other hospital. He would die 1 year later after the first visit to our clinic because of bone metastasis from prostate cancer, suggesting that the paraneoplastic factorinduced RS3PE [28, 29] in this case might explain the steroid resistance observed.

Table 3 demonstrates the distribution of age and sex in patients with PMR or RS3PE syndrome in this study. Out of all patients aged over 50, the rate of PMR was $0.22 \%$ in men or $0.36 \%$ in women, respectively. The rate of patients with RS3PE syndrome was $0.09 \%$ among general population aged over 50. When compared with PMR, the rate of RS3PE syndrome was approximately one-third.

\section{Discussion}

The only population-based study of PMR is from Olmsted County, Minnesota, USA, where the prevalence of PMR is given from cumulative incidence rates [8, 9]. Among persons aged over 50, the prevalence of PMR was 739 per 100,000. Bernatsky et al. [10] have estimated that the prevalence of PMR in Manitobans, Canada, aged over 50 would be approximately 641 cases per 100,000 in urban area and 864 cases per 100,000 in rural areas. These are compatible with the Olmsted County data. In this study, out of 3,347 outpatients aged over 50, 10 patients were diagnosed as PMR, estimating for the first time the rate of PMR is approximately 300 per 100,000 , suggesting that the prevalence of PMR estimated in Japan is not so far from those in USA and Canada.

Previous studies have shown that women are affected two times more often than men [30-32]. The present study revealed that the rate of PMR was $0.22 \%$ in men or $0.36 \%$ in women, respectively, indicating 1.6 times higher prevalence in women. The gender difference in Japan observed in this study furthermore supports the previous evidence observed in western countries that PMR is more frequently in women than men. The average age at diagnosis was 69 in this study, being in good agreement with the previous
Table 3 Age and gender distribution of patients with PMR and RS3PE

\begin{tabular}{|c|c|c|c|c|c|}
\hline Age & (A) Patients & (B) PMR & $\begin{array}{l}(\mathrm{B} / \mathrm{A}) \\
(\%)\end{array}$ & (C) RS3PE & $\begin{array}{l}\text { (C/A) } \\
(\%)\end{array}$ \\
\hline \multicolumn{6}{|l|}{ Male } \\
\hline 0 & 44 & 0 & & 0 & \\
\hline $10-$ & 166 & 0 & & 0 & \\
\hline $20-$ & 471 & 0 & & 0 & \\
\hline $30-$ & 479 & 0 & & 0 & \\
\hline $40-$ & 299 & 0 & & 0 & \\
\hline $50-$ & 406 & 0 & & 0 & \\
\hline $60-$ & 440 & 2 & 0.45 & 0 & \\
\hline $70-$ & 389 & 1 & 0.26 & 2 & 0.51 \\
\hline $80-$ & 141 & 0 & & 1 & 0.71 \\
\hline $0-49$ & 1,459 & 0 & & 0 & \\
\hline $50-$ & 1,376 & 3 & 0.22 & 3 & 0.22 \\
\hline Overall & 2,835 & 3 & 0.11 & 3 & 0.11 \\
\hline \multicolumn{6}{|l|}{ Female } \\
\hline $0-$ & 22 & 0 & & 0 & \\
\hline $10-$ & 232 & 0 & & 0 & \\
\hline $20-$ & 692 & 0 & & 0 & \\
\hline $30-$ & 687 & 0 & & 0 & \\
\hline $40-$ & 430 & 0 & & 0 & \\
\hline 50 & 593 & 2 & 0.34 & 0 & \\
\hline $60-$ & 589 & 1 & 0.17 & 0 & \\
\hline 70 & 530 & 3 & 0.57 & 0 & \\
\hline $80-$ & 258 & 1 & 0.39 & 0 & \\
\hline $0-49$ & 2,062 & 0 & & 0 & \\
\hline $50-$ & 1,971 & 7 & 0.36 & 0 & \\
\hline Overall & 4,033 & 7 & 0.17 & 0 & \\
\hline \multicolumn{6}{|l|}{ Both } \\
\hline $0-49$ & 3,521 & 0 & & 0 & \\
\hline $50-$ & 3,347 & 10 & 0.30 & 3 & 0.09 \\
\hline Total & 6,868 & 10 & 0.15 & 3 & 0.04 \\
\hline
\end{tabular}

evidence that the mean age at diagnosis of PMR was approximately 70 years old [30-32].

To our knowledge, there is no evidence on the prevalence of RS3PE syndrome in not only Japan but also other countries. Based on this study, the rate of patients with RS3PE syndrome in Japan was $0.09 \%$ among outpatients aged over 50. When compared with PMR, the rate of RS3PE syndrome was approximately one-third. However, the number of patients with RS3PE syndrome is quite small in this study, thereby suggesting that a much larger survey should be performed to more accurately estimate the prevalence of RS3PE syndrome in future.

Paira et al. have demonstrated that patients presented clinical characteristics suggestive of paraneoplastic RS3PE had a poor response to corticosteroid therapy [29]. In patients with RS3PE, the presence of systemic symptoms 
along with resistance to low doses of corticosteroid therapy as shown in the present study (No. 2 in Table 2) should alert the physician to the possible presence of malignancy. In fact, the present patient who did not respond to steroid had advanced prostate cancer. Although the serum level of vascular endothelial growth factor (VEGF) or the expression of VEGF in the prostate cancer cells was not examined in this study, we would speculate that increased expression of VEGF in the prostate cancer cells might play a role in the key molecule that induces RS3PE syndrome in the No. 2 patient in this study as following. A couple of reports demonstrated that prostate cancer cells overexpress VEGF [33-36] and overexpression of VEGF increases growth and alters the metastatic potential of prostate cancer cells [37]. Recent evidence has suggested that VEGF may be implicated in the pathogenesis of RS3PE syndrome [21]. These results suggest that VEGF produced by prostate cancer cells is capable of inducing not only tumor development but RS3PE syndrome including pitting edema in the present case (No. 2).

In conclusion, the present study demonstrated that out of 3,347 consecutive outpatients aged over $50,10(0.3 \%)$ or 3 $(0.09 \%)$ patients were diagnosed as PMR or RS3PE syndrome, respectively, in an outpatient clinic where primary care physicians are working in Japan. This epidemiological evidence might help us understand the characteristics of the diseases in primary care setting in Japan.

Open Access This article is distributed under the terms of the Creative Commons Attribution Noncommercial License which permits any noncommercial use, distribution, and reproduction in any medium, provided the original author(s) and source are credited.

\section{References}

1. Michet CJ, Matteson EL (2008) Polymyalgia rheumatica. BMJ 336:765-769

2. Doran MF, Crowson CS, O'Fallon WM, Hunder GG, Gabriel SE (2002) Trends in the incidence of polymyalgia rheumatica over a 30 year period in Olmsted County, Minnesota, USA. J Rheumatol 29:1694-1697

3. Gran JT, Myklebust G, Wilsgaard T, Jacobsen BK (2001) Survival in polymyalgia rheumatica and temporal arteritis: a study of 398 cases and matched population controls. Rheumatology (Oxford) 40:1238-1242

4. Smeeth L, Cook C, Hall AJ (2006) Incidence of diagnosed polymyalgia rheumatica and temporal arteritis in the United Kingdom, 1990-2001. Ann Rheum Dis 65:1093-1098

5. Vanhoof J, Declerck K, Geusens P (2002) Prevalence of rheumatic diseases in a rheumatological outpatient practice. Ann Rheum Dis 61:453-455

6. Chakravarty K, Elgabani SH, Scott DG, Merry P (1994) A district audit on the management of polymyalgia rheumatica and giant cell arteritis. Br J Rheumatol 33:152-156

7. Kremers HM, Reinalda MS, Crowson CS, Zinsmeister AR, Hunder GG, Gabriel SE (2005) Use of physician services in a population-based cohort of patients with polymyalgia rheumatica over the course of their disease. Arthritis Rheum 53:395-403

8. Lawrence RC, Felson DT, Helmick CG, Arnold LM, Choi H, Deyo RA et al (2008) National Arthritis Data Workgroup. Estimates of the prevalence of arthritis and other rheumatic conditions in the United States. Part II. Arthritis Rheum 58:26-35

9. Salvarani C, Gabriel SE, O'Fallon WM, Hunder GG (1995) Epidemiology of polymyalgia rheumatica in Olmsted County, Minnesota, 1970-1991. Arthritis Rheum 38:369-373

10. Bernatsky S, Joseph L, Pineau CA, Belisle P, Lix L, Banerjee D, Clarke AE (2009) Polymyalgia rheumatica prevalence in a population-based sample. Arthritis Rheum 61:1264-1267

11. Nobunaga M, Yoshioka K, Yasuda M, Shingu M (1989) Clinical studies of polymyalgia rheumatica. A proposal of diagnostic criteria. Jpn J Med 28:452-456

12. Yanai H, Yoshida H, Tada N (2009) Clinical, radiological, and biochemical characteristics in patients with diseases mimicking polymyalgia rheumatica. Clin Interv Aging 4:391-395

13. Aoki Y, Iwamoto M, Minota S (2009) Clinical features in patients with polymyalgia rheumatica. Jpn J Clin Immunol 32:274-278 (In Japanese)

14. Shintani S, Shiigai T, Matsui Y (2002) Polymyalgia rheumatica (PMR): clinical, laboratory, and immunofluorescence studies in 13 patients. Clin Neurol Neurosurg 104:20-29

15. Mori S, Koga Y, Ito K (2007) Clinical characteristics of polymyalgia rheumatica in Japanese patients: evidence of synovitis and extracapsular inflammatory changes by fat suppression magnetic resonance imaging. Mol Rheumatol 17:369-375

16. Olivieri I, Salvarani C, Cantini F (2000) RS3PE syndrome: an overview. Clin Exp Rheumatol 18(Suppl 20):S53-S55

17. McCarty DJ, O'Duffy JD, Pearson L, Hunter JB (1985) Remitting seronegative symmetrical synovitis with pitting edema. RS3PE syndrome. JAMA 254:2763-2767

18. Takahashi K, Fujinaga H, Kobayashi M, Naito T, Iida H (2002) Aoki S (2002) Seven cases of remitting seronegative symmetrical synovitis with pitting edema (RS3PE) syndrome. Nippon Ronen Igakkai Zasshi 39:643-647 (In Japanese)

19. Oide T, Ohara S, Oguchi K, Maruyama M, Yazawa M, Inoue K et al (2004) Remitting seronegative symmetrical synovitis with pitting edema (RS3PE) syndrome in Nagano, Japan: clinical, radiological, and cytokine studies of 13 patients. Clin Exp Rheumatol 22:91-98

20. Shimojima Y, Matsuda M, Ishii W, Gono T, Ikeda S (2008) Analysis of peripheral blood lymphocytes using flow cytometry in polymyalgia rheumatica, RS3PE and early rheumatoid arthritis. Clin Exp Rheumatol 26:1079-1082

21. Arima K, Origuchi T, Tamai M, Iwanaga N, Izumi Y, Huang M et al (2005) RS3PE syndrome presenting as vascular endothelial growth factor associated disorder. Ann Rheum Dis 64:1653-1655

22. Bahlas S, Ramos-Remus C, Davis P (2000) Utilisation and costs of investigations, and accuracy of diagnosis of polymyalgia rheumatica by family physicians. Clin Rheumatol 19:278-280

23. Tanno S, Ohhira M, Tsuchiya Y, Takeuchi T, Tanno S, Okumura $\mathrm{T}$ (2009) Frequent early discontinuation of SSRI prescribed by primary care physicians in young males in Japan. Intern Med 48:1263-1266

24. Okumura T, Tanno S, Ohhira M, Tanno S (2010) Prevalence of functional dyspepsia in an outpatient clinic with primary care physicians in Japan. J Gastroenterol 45:187-194

25. Dasgupta B, Matteson EL, Maradit-Kremers H (2007) Management guidelines and outcome measures in polymyalgia rheumatica (PMR). Clin Exp Rheumatol 25(Suppl 47):130-136

26. Bird HA, Leeb BF, Montecucco CM, Misiuniene N, Nesher G, Pai $S$ et al (2005) A comparison of the sensitivity of diagnostic criteria for polymyalgia rheumatica. Ann Rheum Dis 64:626-629 
27. Bucaloiu ID, Olenginski TP, Harrington TM (2007) Remitting seronegative symmetrical synovitis with pitting edema syndrome in a rural tertiary care practice: a retrospective analysis. Mayo Clin Proc 82:1510-1515

28. Cantini F, Salvarani C, Olivieri I (1999) Paraneoplastic remitting seronegative symmetrical synovitis with pitting edema. Clin Exp Rheumatol 17:741-744

29. Paira S, Graf C, Roverano S, Rossini J (2002) Remitting seronegative symmetrical synovitis with pitting oedema: a study of 12 cases. Clin Rheumatol 21:146-149

30. Bahlas S, Ramon-Remus C, Davis P (1998) Clinical outcome of 149 patients with polymyalgia ehumatica and giant cell arteritis. J Rheumatol 25:99-104

31. Salvarani C, Cantani F, Macchioni P, Olivieri I, Niccoli L, Padula A et al (1998) Distal musculoskeltal manifestations in polymyalgia rheumatica. Artheritis Rheum 41:1221-1226

32. Huchings A, Hollywood J, Lamping DL, Pease CT, Chakravarty K, Silverman B et al (2007) Clinical outcomes, quality of life, and diagnistic uncertainty in the first year of polymyalgia rheumatica. Arthritis Rheum 57:803-809
33. Li R, Younes M, Wheeler TM, Scardino P, Ohori M, Frolov A et al (2004) Expression of vascular endothelial growth factor receptor3 (VEGFR-3) in human prostate. Prostate 58:193-199

34. Tsurusaki T, Kanda S, Sakai H, Kanetake H, Saito Y, Alitalo K et al (1999) Vascular endothelial growth factor-C expression in human prostatic carcinoma and its relationship to lymph node metastasis. Br J Cancer 80:309-313

35. Zeng Y, Opeskin K, Baldwin ME, Horvath LG, Achen MG, Stacker SA et al (2004) Expression of vascular endothelial growth factor receptor-3 by lymphatic endothelial cells is associated with lymph node metastasis in prostate cancer. Clin Cancer Res 10:5137-5144

36. Jennbacken K, Vallbo C, Wang W, Damber JE (2005) Expression of vascular endothelial growth factor C (VEGF-C) and VEGF receptor-3 in human prostate cancer is associated with regional lymph node metastasis. Prostate 65:110-116

37. Tuomela J, Valta M, Seppänen J, Tarkkonen K, Väänänen HK, Härkönen P (2009) Overexpression of vascular endothelial growth factor $\mathrm{C}$ increases growth and alters the metastatic pattern of orthotopic PC-3 prostate tumors. BMC Cancer 9:362 